\title{
Enabling Communities for a changing climate: re-configuring spaces of hazard governance
}

\section{Abstract}

The last ten years have witnessed increasing levels of concern and public debate about the risks associated with environmental hazards such as flooding in the UK and the likelihood that these will increase in frequency due to anthropogenic climate change. In this paper, we argue that attempts to mitigate this process through a focus on individualised risk communication and behavioural change are unlikely to be successful, given the epistemic conflicts surrounding climate change knowledges in public discourse. In response, we argue for an alternative framework for developing environmental knowledges using social learning to promote both epistemic re-alignment and a re-scaling of environmental governance that promotes enablement. We use insights from research on flooding in South West England to highlight the ways in which traditional policy approaches such as behavioural change have come to be so overbearing in public debate on environmental hazards management. In contrast, we demonstrate the potential for a re-scaling of environmental governance to reconfigure climate change knowledge and build new spaces for enablement to reduce hazard vulnerability at the place-based community scale. We argue that this has major epistemological and practical implications for the ways that researchers and policy makers work with publics to reduce hazard risk under a changing climate. 
In recent years the public profile of environmental hazards in the UK has become characterised by a widening epistemic gap concerning the causes of extreme weather events, flooding and periods of drought (Hulme, 2009; Stott et al., 2016). On the one hand, those working within the field of climate attribution are becoming more confident in the ability of science to attribute extreme weather events to anthropogenic climate change (Stott et al., 2016). In contrast, so-called climate change deniers and sceptics argue that it is both impossible to link such events and they also question the foundational science on which the climate change thesis is constructed (Mann and Toles, 2016). However, this epistemic division is not limited to discussions of climate change, but also incorporates the role of science and scientists in understanding and responding to environmental hazards (Mooney, 2008). For example, the major flooding witnessed on the Somerset Levels in the winter of 2013/14 in the UK sparked a national debate over the role and effectiveness of dredging as a flood prevention measure; something that was regarded as vital by many locals, but which was resisted by the UK's Environment Agency (Smith et al., 2017). As a result, public discourse on issues such as flooding has progressively become marked by fractious exchanges between members of the scientific community and a range of publics and campaigners, who contest the scientific basis for decision-making.

In this paper we argue that these high profile controversies are representative of the ways in which publics are frequently positioned as sets of individuals who need to be engaged through the effective delivery of scientific knowledge to meet 'informational needs' (Wong-Parodi and Strauss, 2014). Accordingly, the 'problem' of how to engage publics with climate change and environmental hazards has conventionally been regarded as one that is attributable to the (poor) communication of science and an apparent lack of understanding by publics of climate change and also physical processes (Moser, 2010). In line with other commentators (Barr, 2014; Blake, 1999; Owens, 2000; Shove, 2010) we argue here that such 'deficit' approaches towards knowledge production and acquisition have led to a dis-empowered and dysfunctional form of environmental governance that simultaneously distances scientific experts and expertise from publics, whilst also prescribing narrowly framed behavioural changes for individual citizens. Through such processes, environmental knowledge becomes both expertised and individually prescribed. We argue that this has major implications for the ways that environmental hazards are governed and the role that citizens can collectively play in understanding the ways these can be understood and managed. Our proposition is for a re-scaling of knowledge-making and environmental governance that challenges the binary of 'expert versus individual' to examine the role and potential of enabling community knowledge brokering to governing environmental hazards. Through this process, we aim to explore how discourses on knowledge controversies like climate change can be made less oppositional. Moreover, 
we seek to demonstrate how a re-scaling of hazard governance can provide opportunities for empowerment that are lacking in current approaches.

In this paper we focus on river, surface water and coastal flooding in the IK, an issue that has gained greater prominence in the UK as communities have been inundated in successive periods of extreme weather (Centre for Ecology and Hydrology, 2016). Beginning with the summer 2007 floods across large parts of England, in which major infrastructure was disabled, there have been growing calls for both strategic national and local action to reduce flood risks (HM Government, 2008; 2016), which were given renewed impetus by the severe flooding of the winter of $2015 / 16$. As the recently published National Flood Resilience Review argues (HM Government, 2016, p. 1), the emphasis is very much placed on the resilience of physical infrastructure and delivery of key services:

"As part of this review we have secured commitments from the water and telecommunications industries to make their infrastructure more resilient. In addition, this year the Environment Agency will be able to deploy four times more temporary barriers to protect our communities than last winter. As these plans are completed, we are confident that our communities will be better protected. They can have confidence that the essential services they rely on will be even more resilient to the kind of extreme weather we saw last December".

Alongside this review of physical resilience, there have also been strident efforts to persuade householders to prepare for flood events, most recently through the Environment Agency's Floods Destroy: be prepared campaign (Environment Agency, 2017) in which individuals are encouraged to make a flood plan and are offered advice on what to do before, during and immediately after a flood. A key component of this campaign is to provide warning systems that indicate the severity and imminence of a flood event, alongside the longer-term goal to encourage householders to make physical adjustments to properties to reduce the disruption of clearing up after floods. However, although physical defences and individual preparedness have roles to play, both of these approaches rely on forms of resilience that are either 'delivered on a lorry' or contingent on an individual's ability to plan and cope with a flood event, both of which are illustrative of the binary that has been created between 'expert' and 'individual'. In contrast, we present here a place-based community approach towards co-constructing knowledge about flood risk and argue that this scale of knowledge coproduction presents opportunities for generating longer-term and embedded community resilience to hazards (Brown, 2016; Carnegie Trust, 2011; Hopkins, 2008). We do this in recognition of three key intellectual and political developments that are changing the ways in which flooding, and by implication environmental hazards, are understood in contemporary developed societies. First, the field of flood prevention policy is now a firmly established area of scientific controversy, in which a 
range of publics and interest groups have become empowered to contest and challenge traditional scientific expertise (BBC, 2014; Owens, 2015). Such discourses have been recently exacerbated by a wider sense that scientific knowledges may even work against the interests of local publics (Barr, 2017). Second, it is now becoming clear that flooding is likely to become a more widespread problem in the face of the changing risk profiles associated with anthropogenic climate change, which mean that more homes and communities are likely to be flooded more often as a result of extreme weather events (IPCC, 2015). As such, coping with floods may become a regular activity and might mean that some communities who have not experienced flooding in living memory will begin to do so. Third, there is a growing gap in flood prevention and recovery policy between strategic investment in largescale physical defences in high risk localities and the emphasis placed on individual household preparations for flood events. In the space between these two policy priorities are communities that may not be strategically deemed worthy of flood defences, but nonetheless need to cope when floods occur. Accordingly, a space of need emerges where communities may have to assume some of those roles formerly played by the local state.

We argue here that these three issues (changing knowledge frameworks, anthropogenic climate change and shifting community-local state relations) together present an opportunity to explore how community resilience to flooding could be practiced differently to provide a way of enabling longer-term and embedded resilience. We propose that this could be achieved through directly tackling the issue of knowledge controversies and climate change through a place-based approach (Lane et al., 2011) by using a social learning methodology (Blewitt, 2006; Pahl-Wostl, 2006). In so doing, we argue that greater acceptance, ownership and control over flooding issues could be achieved through a process of enablement, in which the practice of learning together re-positions the role of publics from being engaged, to learning how to become empowered.

The paper is structured in the following way. First, we consider the ways in which knowledge controversies surrounding environmental hazards, and flooding in particular, are re-framing the relationships between citizens, the state and science. In particular, we demonstrate how knowledge controversies frequently reflect the different hierarchies of knowledge used for policy making and the ways in which non-standard public knowledges can often be crowded out. Second, the paper considers how such knowledge controversies often become focused on discourses surrounding the science of anthropogenic climate change. This has led to significant challenges for the promotion of climate change knowledges, especially as anthropogenic climate change is often framed at a global, rather than local scale. We therefore propose that one way to approach these kinds of knowledge controversy is through a hazard and place-based lens, in which conversations about climate change are contextualised through an existing hazard. Third, we illustrate the potential of such an approach 
through deploying a social learning methodology, in which community members learn to develop knowledge about the environment in a collaborative setting. Using an empirical example from Devon (UK), we demonstrate how knowledge controversies, and climate change knowledges in particular, can be worked through by social learning processes that utilise a range of knowledges to explore a specific and recognised threat. Accordingly, the paper proposes ann intellectual framework for social and physical scientists working on knowledge controversies, in which social learning, rather than often passive forms of engagement, is used as a process to foster community resilience in the face of environmental change.

\section{2. 'Be prepared!' Governing hazards from a distance}

There is a long and established literature in the field of environmental hazards research that has sought to understand the influences that act on individual hazard perception (Slovic, 2000; 2010). As Lupton (2013) has noted, this has drawn heavily on the discipline of psychology and has explored the role of cognitive processes for understanding and reacting to hazards. Indeed, Slovic (2000) has outlined the use of psychometric techniques for understanding hazard perception, which has spurred a range of intellectual debates on how hazard perceptions can be conceptualised and measured. Such research has often adopted particular conceptual or analytical frameworks for exploring attitudes towards hazards and the propensity for individuals to take mitigative action (e.g. Paton 2003). Moreover, the use of this kind of individualised approach to hazard perception is without doubt that which has been preferred as a means of reducing hazard risk to populations. Take, for example, the conclusions of the Pitt Review (HM Government, 2008, p. 315) on the UK's summer 2007 floods:

"We need to educate the public about flood risk...The Environment Agency estimates around 75 per cent of people who receive a flood warning currently take some form of action. While this is encouraging, it also indicates that one in every four people aware of a flood warning does not take effective action to limit the impact on themselves and their families".

The emphasis placed in this review highlights the role that encouraging awareness raising, education, knowledge acquisition and translating this into behavioural changes has had on policies aimed at reducing hazard risk. In broad terms, this has been referred to as a problem of 'Awareness, Information, Decision and Action' (AIDA), in which there is a 'value-action' gap between stated levels of knowledge and awareness, and reported decisions to take mitigative actions (Barr, 2003; Blake, 1999; Kolmuss and Agyeman, 2002). Importantly, a range of research projects have emerged that have attempted to conceptualise the challenge of hazard risk reduction through the lens of the individual by examining a range of psychological constructs. Examples related to flooding concern research have explored notions of individual information seeking (Griffin et al., 2009; Kellens et al., 2012), the 
perception of coastal flood and riverine risks (Kellens et al., 2011; Miceli et al., 2014), understandings of individuals' willingness to adapt to future flood risk (Keogh et al., 2011; Kievik and Gutteling, 2011; Lieske et al., 2014) and perceptions of past and experience and trust in framing flood risk perception and personal preparedness (Wachinger et al., 2013).

We can interpret this focus in two distinct ways, which connect to political and epistemological problems. First, we can view an emphasis on the role of individual decision making from what we term here as the political economy of behavioural psychology. In this interpretation, we argue that shifts in the political economy of nations like the UK have led to a framing of social and environmental policy through the lens of what Clarke et al. (2007) refer to as the citizen-consumer. In this framing, a rolled-back state (Jessop, 2002; Rose and Miller, 1992) comes to progressively rely on the logic of neo-liberal values for governing (Giddens, 1991), where consumer choice is framed as the most rational and apparently ideologically free arbiter in making decisions. In this way, the dogma of regulation and state-led decision-making is replaced by free market mechanisms that are selfregulating. Within the context of hazards research, the logic applied would mean that households have free choices about whether or not they choose to prepare for something like a flood event - the logic of the market being that people will elect to protect themselves through taking preventative measures, from home insurance to filling sandbags. However, Clarke et al. (2007) and Jones et al. (2011a) have argued that despite the logic of these apparently free market mechanisms, there is an implicit recognition by government that such approaches are, in isolation, prone to failure (due to, for example, financial constraints or a belief that it is the state's role to provide protection); hence the need for a second dimension, that of citizenship. This component of the citizen-consumer is imbued with the personal responsibility for making what DEFRA (2005) referred to as 'better choices'. Despite the logic of the market, there are certain and prescribed ways of behaving appropriately, which form the basis for campaigns to elicit behavioural change. In this way, particular choice architectures (Thaler and Sunstein, 2008; House of Lords, 2011) are designed and mobilised to promote particular kinds of choice. As such, 'choice' is a tightly constrained selection of individual elements; there is no scope for people to consider alternatives, to question the logic of the choices that confront them, or to dispute the political philosophy that uses persuasion as a tool of governance.

A second interpretation of why the AIDA logic of behavioural change has become so prominent leads us towards an epistemological divide in how policies for behavioural change are framed. We argue here that current behavioural change approaches do not represent the possibility offered by interpreting behavioural change across scales, but rather constitute a particular and psychologically driven approach to change. This is something that geographers have noted in relation to a raft of UK Government policy on changing behaviours (Jones et al., 2011a; 2013; Whitehead et 
al., 2011) in which there has been a progressively important focus placed on the use of behavioural economics to promote the Nudge agenda and forms of social marketing to promote change (French et al., 2009). Such an approach has been mobilised through the Government-inspired Behavioural Insights Team (2016), which has developed a range of research and policy initiatives to promote individual behaviour change, from health and wellbeing to crime. In its 2015 annual report (p. 5), it noted that:

"while many of the academic findings from the behavioural science field originate from US research, the UK Government was now considered to be the global leader in application of the field...[A]lmost every government department is now using behavioural science to help improve the way that public services are run or policies are delivered".

The development of this highly centralised approach to governing at a distance (Jessop, 2002) has been characterised as a major shift in the way that the UK Government seeks to deliver public policy goals and has been characterised by Jones et al. (2011a, p. 497) as follows:

"Using the new sciences of choice from psychology, economics and the neurosciences - as well as appealing to an improved understanding of decision-making and behaviour change - a libertarian paternalist mode of governing is being promoted in the UK".

As such, disciplines like psychology, neuroscience and behavioural economics are enabling governments to deliver agendas focused on the responsibilisation of individuals through the mechanism of state-led paternalistic approaches that encourage individuals to make particular choices. Yet we argue here that this only represents part of the story for social scientists and those interested in generating long-term behavioural change. Shove $(2010 ; 2011)$ has suggested that current formations of behavioural change research are both narrowly defined and disconnected from the social, historical and cultural contexts in which practices occur. Indeed, this divide is witnessed through the willingness of academic researchers to address questions of individual behaviour change, despite the mounting evidence that deeper social and political processes are prominent in framing hazards (Lupton, 2013; Collins, 2008) and the critical role that place-based community initiatives can play in promoting resilience to hazards (Berkes and Ross, 2013; Lane et al., 2011; Ross and Carter, 2011; Whatmore, 2009). In this paper, we therefore argue that this connects to a broader privileging of individualistic and cognitive discourses that present 'behavioural change' in a particular formation - one that is both narrow and intellectually unambitious. We argue that this is the case because of a progressive politics of individualism that has driven down the challenge of dealing with a range of social and environmental problems to the individual scale. 


\section{Contested knowledges in a changing climate}

The focus on individuals as the primary units of change is clearly represented by the efforts made to promote awareness to publics about the threat of environmental hazards. Yet alongside the arguments of social scientists who contest state-led paternalistic approaches (Jones et al., 2011a; 2011b) lies the proposition that the ways in which environmental knowledge is constructed and communicated is indicative of rationalistic forms of decision making and behaviour change (Owens, 2000; Shove, 2010). Accordingly, we argue here that not only do the policies originating from a paternalistic approach represent a narrow configuration of decision making, but they also create a binary between 'scientific' and 'lay' knowledges that is dis-empowering. This binary becomes specifically relevant when considering the ways in which flood risks are framed by the rising importance associated with climate change predictions that suggest flooding will become an increasingly prominent climate impact as rainfall intensities change (IPCC, 2015). Accordingly, as future flood risks are intimately associated with climate change science, the controversies surrounding climate science have significant implications for how flooding is understood and the degree to which future predictions are accepted.

If we start by considering traditional forms of science and risk communication, it is clear that these are based on what Blake (1999) referred to as a deficit model of decision making, in which a lack of objective knowledge is the primary cause for 'inappropriate' actions. Such deficit approaches are of course greatly enhanced by the considerable investment in psychologically-informed research through cognitive and psychometric studies (Lupton, 2013) that speak of the role of objectified and official forms of knowledge. Yet researchers from the field of Science, Technology and Society (STS) studies have for several decades been highlighting the evolving problem of creating a binary expert and lay approach to knowledge creation and communication (Chilvers and Kearns, 2016; Chilvers and Longhurst, 2016; Callon, 1999; Wynne, 1992). For example, researchers have highlighted the ways in which public and media discourses on climate change have progressively questioned the scientific basis for climate change (Akerlof et al., 2012; Barr, 2011; Carvalho and Burgess, 2005; Corner et al., 2012; Shukburgh et al., 2012; Whitmarsh, 2009), which has also been reflected in the politicisation of climate science (and many other forms of science) in the United States (Gauchat, 2012; Mooney, 2013). Indeed, Hulme (2009) has highlighted the role of what he terms 'epistemic hegemonies' that have emerged within climate science, which can seem overly protective and bounded (Demerrit, 2001a; 2001b). As such, an oppositional discourse has emerged between so-called climate change sceptics and deniers and the majority of the climate science community (Leiserowitz et al., 2013; Maibach et al., 2012; Nerlich, 2012). 
Such an oppositional discourse highlights the challenge that those attempting to communicate climate change face, not least because the line of contestation appears to be set along the boundary of what constitutes valid scientific knowledge. Yet here we argue that the issue has less to do with what constitutes fact or opinion (Funtowicz and Ravetz, 1993; Funtowicz and Ravetz, 2013) but rather the processes through which science becomes knowable and the ways in which this is negotiated and scaled. In recent years there has been considerable discussion within STS studies concerning the ways in which scientists can work with publics to both challenge knowledge hierarchies and also co-produce knowledge using a range of alternative methods. Such a move to post-normal science (Lupton, 2013) develops the early thinking in this field from Callon (1999), Funtowicz and Ravetz (1993) and Oppenheimer (2005) who have argued for new models of knowledge creation and learning that recognise ontological diversity and the contested and provisional nature of knowledge. This has to do with both the nature of knowledge and the modes of enquiry that lead to its acquisition and acceptance. Funtowicz and Ravetz (1993, p. 739) describe it as follows:

"Whereas science was previously understood as steadily advancing in the certainty of our knowledge and control of the natural world, now science is seen as coping with many uncertainties in policy issues of risk and the environment. In response, new styles of scientific activity are being developed. The reductionist, analytical worldview which divides systems into ever smaller elements, studied by ever more esoteric specialism, is being replaced by a systemic, synthetic and humanistic approach. The old dichotomies of facts and values, and of knowledge and ignorance, are being transcended".

Our argument therefore is that hazards researchers need to consider the ways in which issues like climate change, and more specifically flood risk, are representative of both shifting knowledge hierarchies and also changing modes of scientific enquiry. This builds on evidence provided by Lane et al. (2011) and Whatmore's (2009) research in the UK, which has demonstrated the benefits of the knowledge creation process and engaging modes of citizen science-based enquiry. In their research on flooding in the Yorkshire town of Pickering, they sought to address the issue "...of what happens when local people and academics are involved in the knowledge production process from the outset through an experiment in doing (flood risk) science differently" (Lane et al., 2011, p. 17). In what they refer to as 'radical scientific method', Lane et al. have argued for a re-distribution of expertise and a broader acceptance of outcomes that draw upon expertise and methods alongside the traditional scientific community. In their research in Pickering, the Ryedale Flood Research Group was able to use a range of knowledges from publics to construct an understanding of natural environment processes and propose an alternative to the officially prescribed approach to flood prevention. In this way, Lane 
et al. (2011, p. 30) explain this approach as one where: "What we have done here is moved the idea that a model should travel, to one where the process of model building should travel".

In the remainder of this paper, we use empirical data from a community flood resilience project in South West England to make three interventions about the production of hazard knowledges and their role in promoting community resilience within the context of anthropogenic climate change. First, we suggest that successive decades of risk communication have resulted in a set of knowledges and ascriptions of responsibility that have de-centred and dis-placed risk away from the community scale, to either the individual or those authorities who are deemed to hold power. In other words, we seek to understand how communities can re-engage with the process of knowledge generation and resilience building to become empowered to understand and manage risk collectively. Second, we argue that in attempting to re-scale efforts to engage publics, we encounter a process of negotiating knowledge hierarchies, through a gradual re-shaping of knowledges, trust and accountabilities. In this way, place-specific climate knowledge is explored not through the (oppositional) discourse of global climate science, but rather in a specific context and through a process of engaged negotiation. Third, we argue that new scales of resilience can therefore emerge through collaborative working that raise both hopes and challenges for (re)vitalising ambitious community-scale responses to environmental change and in so doing provide scope to re-cast behavioural change as something that is both collective and far-reaching.

\section{Social learning to promote resilience}

The research on which this paper is based deployed a social learning methodology to examine the ways in which environmental knowledge could be co-constructed and deployed to explore alternative governance frameworks. Social learning within the field of environmental hazards is often viewed as a practical tool for adaptation research (Berkes, 2009) and is designed to engage communities (rather than individuals) in new forms of data gathering and public science practices (Becu et al., 2016; Lanfranchi et al., 2014. These might include forms of citizen science, public data gathering and the integration of various types of knowledges, such as archival data, eyewitness accounts, oral histories and tacit knowledge of local environmental conditions, alongside conventional scientific data (McEwan et al., 2011). In so doing, social learning aims to practically resist existing hierarchies of knowledge through practicing public science differently (Lane et al., 2011; Whatmore, 2009). PahlWostl $(2006$, p. 3) argues that social learning processes are:

“...codified in shared practices, tools, concepts, symbols, or material artefacts embedded in a context of meaning...[L]earning will not only remain in the cognitive realm, but.... will lead to joint practices and collective action (Pahl-Wostl, 2006, p. 3). 
In practice, social learning takes several forms, which largely depend on the degree of leadership from any one entity. In our research, we utilised Pahl-Wostl's (2006) 'Stakeholder process' interpretation of social learning, in which a broad range of stakeholders, including publics, are involved in knowledge acquisition and in which leaders emerge as part of the process of knowledge brokering and activity planning. Accordingly, the data on which this paper is based was gathered as part of a UK Economic and Social Research Council (ESRC) funded project, which aimed to explore the potential for social learning to develop local knowledges about flooding and the likely vulnerabilities from climate change.

The research was undertaken in the market town of Crediton, Devon, which is located in South West England, approximately 8 miles north-west of the city of Exeter. Crediton has a population of 7,600 inhabitants (Devon County Council, 2017) with a situation just north east of the confluence of two rivers, the Creedy and Yeo. The lower lying outskirts of the town are on the floodplains of these rivers, but most of the town is situated on steeper ground, with the High Street occupying a point just above a valley bottom, under which a culverted stream flows.

During the winter of 2014-15 the authors were approached by Devon County Council's emergency planning department to explore the potential for exploring a knowledge co-production approach to developing greater collective knowledge and activism for reducing flood risks in the town. Crucially, the town doesn't currently have a major and systematic problem with flooding, but emergency planners had identified it as a site, because of its steep topography, where surface water flooding is a major risk and where these risks could increase due to increased storm intensity as a result of anthropogenic climate change.

The research was led by the authors, one a human geographer and the other a physical geographer with interests in climate change science and science communication. Four formal partners were involved in supporting the project: Devon County Council, Climate Outreach, the Devon and Somerset Fire and Rescue Service and Crediton Town Council. Along with these partners, the research aimed to convene a competency group of around twelve individuals from in and around Crediton to participate in four discussions connected to flood risk in the town, the potential for future flooding and the ways in which this could be addressed. The schedule and scope of the four sessions were deliberately open to allow the group to formulate and drive its own agenda, but the topics for discussion were derived by the academic participants and were designed to respond to the following four broad themes:

(1) Group working, social learning and introducing our perspectives on flooding;

(2) Understanding flooding in Crediton through the evidence we bring;

(3) Future flooding risks, including discussing climate change impacts; 
(4) Developing ideas to reduce flood risks in the future.

Although climate change as a theme was only explicitly signalled and discussed in the third workshop, it became a topic of discussion in all four group meetings, as participants were aware of the popular media discourses surrounding flooding, climate change and policy from the Somerset Levels flooding in 2014 (BBC, 2014). Meetings were held in a hall belonging to the local Methodist Church and were informal, round-table discussions for two hours each. Although the lead author of this paper facilitated each session, the aim was to progressively reduce academic input throughout the project to provide the opportunity for alternative leaders and facilitators to emerge in the group and to remove the risk that the group might defer to perceived kinds of academic expertise, therefore stifling other voices. This was achieved through both a directed and also organic process; the facilitator encouraged group members to develop their ideas and bring these as lead discussion points to subsequent sessions, but it was also the case that members also arrived at group meetings prepared (and un-prompted) to discuss the research they'd been undertaking.

The group members were selected through an open invitation to participate through a letter of invitation distributed via an existing contact in the town in the local Transition initiative (Sustainable Crediton), where we broadly specified that a range of participants were welcome: residents, those with experience of flooding, emergency responders and planners, and members of the Town Council. Due to the significant time commitment required to participate in the research and the voluntary nature of the commitment, obtaining both a sample representative of many diverse interests and ensuring sustained participation was challenging and some key voices are likely to have been absent from the group, such as those representing farming and business interests. Table 1 provides an overview of the group's participants and their role and expertise, and all those within the group were invited to an initial workshop where a group working session was facilitated.

All the group sessions were recorded using a voice recorder and, in line with the written consent provided by each participant, were fully transcribed by an external agency. The transcripts were initially coded using an open method, focusing on familiarity with the transcripts and identifying key points of discussion and narrative (Cope and Kurtz, 2016). In the second phase, axial coding was deployed to follow key themes identified by the initial coding process, with a final set of detailed codes being identified through selective coding (Strauss, 1987) to form the basis of the data presented in this paper.

The following sections pursue three arguments. First, we demonstrate how the particular scaling risks in the UK has promoted a landscape of oppositional discourse on responsibility for flood prevention and mitigation. We show how cultures of responsibility are scaled either at the individual 
or local state level, without reference to community level activism. Second, we explore how the process of discussion can lead to an ongoing process of negotiating knowledge hierarchies and knowledges that provides a potential way to explore controversial issues such as climate change, within a local context. Third, we examine how community level activism may provide a way for recasting the debate on individual behavioural change, albeit with major challenges in the ways in which such a process can be co-managed.

\section{Dis-connected flood responsibilities}

Flood prevention and mitigation in the UK has traditionally been within the purview of state agencies and local authorities, who provide flood prevention schemes, flood warnings, emergency planning, highways maintenance and planning functions. Alongside this scale of governance, there has been a focus on the personal preparedness of individuals and households, to react to flood warnings through taking specific kinds of action. As we have argued, this represents two alternative narratives of resilience using different scales, but both of which are framed by 'governing at a distance' (Jessop, 2002). In the workshops, the sense that the state had a role to play became immediately apparent through the lens of flood prevention and infrastructure maintenance:

"I hate to say, Highways, I think, are the biggest culprit here - and I'm not going to bring... I've got reams of evidence to support that statement. There isn't the money in the county council now to maintain the major roads, let alone the minor roads. Minor roads are being abandoned" (DA).

"The road outside Bude Cottage, I think, tends to flood more easily when the drains don't get cleared, so that comes back down to the county council" (GT).

In this particular locality, the workshop participants identified a particular link between highways maintenance, drain clearing and the changing land management practices on steep-sided fields adjacent to roads. As the following extract describes, the role of traditional sediment traps such as hedgerows, were viewed as critical for flood prevention:

"But if the farmers looked after their banks, their hedgerows, and their ditches, and if the landowners maintained their hedgerows and their ditches properly, then I honestly believe the biggest portion of the flooding would be prevented. The other thing that's happened is the changing farming practices. Intensive farming now is washing silt off...we got classic examples, half of one of his fields slid down, that's virtually submerged his back door. So, but I will stand by what I said - the world is changing, people used to take responsibility for their land. They don't any more" (DA). 
"And so, to me, there seems to have been a connection, as a resident, between ditching activities and less flooding on the lanes. Also, my understanding of some of the Devon ditching is that traditionally, farmers would ditch at the low end of a field. Now, that wasn't to take the water anywhere else, it's to catch water and runoff. And the topsoil, which is hugely valuable and nutritious, they could put it back on the land. And they don't do it anymore, and I have to admit - and I won't name who, or which agency - but I had a discussion with a particular agency, and they refused to accept that fact" (HW).

These extracts demonstrate the way in which flood management within a catchment setting is often framed in oppositional terms and so-called 'responsibility' is externalised to the state or other actors. Moreover, they demonstrate how the state is often regarded as the natural regulator of practice, through which all decision-making must be passed. These examples therefore illustrated the ways in which dealing with an environmental hazard is understood as being complex, but the architectures of governance dis-empower communities to tackle embedded practices and expert knowledges. However, through our discussions, the group also narrated flooding as something that can also be cast as an individual responsibility, a pervasive narrative that has emerged in recent years through the proliferation of behavioural change campaigns:

"But they really ought to be having a pair of Wellington boots somewhere...and you need to have a shovel you can go out and clear a drain" (GT).

"I've got a feeling, that it's down to individuals that live in vulnerable areas, thinking, 'Actually, I need to lift my plugs and make them higher, and maybe I don't have carpets on the ground floor - I have rugs that I can pull up'"(JS).

These examples highlight both GT's personal experiences of being flooded and taking practical action within the home to prevent future flooding, alongside a sense that there were longer-term adaptive measures that individual householders could enact to reduce their vulnerability if they were flooded. Moreover, workshop participants recognised the changing relationship between the local state and individuals and the ways the state was 'rolling back' (Jessop, 2002) through the recent process of local government spending and service reductions:

"And it's nice to say, 'Well, the council - let's tell the council about this, because then they can [do] whatever', but I don't think the council have the finances, the time, or whatever, to do that. And I think the place that they are in at the minute is actually pushing it back to individuals" (JS).

We present these narratives in this way because we want to give the essence of what started in our first workshop as a negative framing of flood risk; it was framed as someone else's responsibility - either the local state, landowners or individuals who were at risk. We argue here that our experience 
at this initial workshop connects with the ways in which environmental hazards are framed as externalised, to be dealt with by authoritative state action or pushed down to the individuals who happen to live in high risk localities. Yet we asked ourselves, where might there be a space for reconfiguring the debate to recognise the knowledge complexities involved and for a role for communities to fill the yawning gap between experts and individuals? In doing so, we began to explore the ways in which the group could tackle an understanding of flooding, its causes and its connections to climate change.

\section{Negotiating knowledge hierarchies}

A second feature of flood planning has been the reliance on official and conventional scientific knowledge about flood risk and the ways this has led to the gap in trust and empowerment between communities and institutions. The out-turn of this process has been to create an extensive architecture, aesthetic and lexicon of flooding: from the paternalistic discourses of flood 'protection' and 'resilience' to the creation of flood maps for communicating risk and the translation of scientific data into individual insurance premiums. Yet these data streams emanate from one particular epistemic approach to knowledge generation and we argue here that it contributes to a disconnection between communities and their understanding of the local environment. Moreover, we argue here that other knowledges can be both affirming and have greater traction.

The process we developed in the workshops was to enable participants to share their experiences of flood events, their observations and knowledge from a range of sources (historical documents, shared or individual memories, photographs, maps, newspaper articles etc.). Figures 1 and 2 present a summary of the group's findings through two posters that were designed for a public exhibition in the town's community bookshop in the September of 2015 , at which visitors could add knowledge to a flood map, identifying places which they knew were prone to flooding and those that posed future vulnerabilities. Importantly, this map showed the existing scientifically-based risk for a 1 in 100 year flood.

Much of the initial discussion within the workshop group focused on historic floods and lowerlying parts of the town, but there was recognition that even those areas well above river level were vulnerable due to the steep topography. Moreover, the local historian in the group reminded participants of the water course still present, but buried in a culvert underneath the town's main street, an area which was largely regarded as entirely risk free from flooding:

"Because just to the north side of the High Street, from the top end of town, The Green, running right down through, underneath the town square, underneath Newcombe's Meadow, 
is something called The Litterburn, which was an open stream, until the beginning of the nineteenth... first half of the nineteenth century" (FA).

"Their doors are basically all high above the road, with steps up, and each of the doorways has got two wooden panels, so it's obviously been a historic issue" (KQ).

Indeed, the initial perception amongst most group members that 'Crediton doesn't flood' was progressively challenged by two members of the group who spent several days in newspaper archives, revealing stories of intense rainfall events and flooding in and around the town. Indeed, through this process participants began to reveal a range of flood events that had occurred in living memory, and importantly began to link these to changes in the town's built environment:

"Just a short one...This is up in Westernlea...a fairly new housing development, nineteen eighties, nineteen nineties. And on one edge of this there's high ground - this is not a massive hill, but it's a hill which rises just off to the west of it - and soon after that road was built, a number of houses suddenly found themselves flooded one day after heavy rain, which just came down off the hillside, no watercourses there, just off the hillside, going towards the stream which is obvious, flows just along the bottom there, and was suddenly coming through people's houses...But just how simply a new development created an unexpected problem, which no-one was aware of" (BH).

However, the group spent most time and energy considering future vulnerabilities, which was where climate change was explored in explicit detail. The narrative of climate change was not explicitly introduced as a discussion topic for the group at the start, but from the very beginning of the workshops, it was frequently mentioned and often framed in a conflictual manner between individual participants who shared opposing views on the science of climate change:

“... and I do hope that this exercise is not to justify the statement that 'global warming is causing this', because you have to prove it as far as I'm concerned, but if one of the things that I see is that some of these flash flood type events... well, they're not a recent event, I have to say, but they've been going on for some time. And if you actually analyse the risks to life and ... you'll have to dig me out of a grave" (DA).

Yet the common concern of the group, to explore flooding, appeared to be able to moderate the discussion of climate change through finding the 'common ground' of understanding the threats to a specific place:

"Without knocking you off your perch, I think you and I disagree about some things, but the common ground is that with stuff like farming practices and what they do in culverts and what have you, you can do something about that stuff, so it's about... in my view, it's very well worth doing anyway, clearly" (HW). 
Accordingly, the group negotiated a way forward that was able to integrate climate change knowledge into the wider and practically-focused work of the group. Implicit to this was an acceptance and appreciation of the diversity of knowledge in the group. Moreover, through exploring the role of climate change in this setting, without placing a hierarchy or preferring some knowledges over others, the group was able to reach a consensus on how they could advance their work:

"Clearly people have different thoughts around climate change...And so there are things which we have in common, and there are things which we can plan to do, both at that strategic level, and at that local level. So I would think, if we could come up with some shared conclusions, even at that level, that would be a useful starting point really, to further discussions, further debate. And this is the sort of thing we can share with others" (BH).

In this way, the discussion focused on what the group sought to achieve in a particular place (flood resilience) rather than questioning the scientific basis for particular climate change predictions. In so doing, the group was able to embrace difference and feel empowered to share those differences with a wider audience.

\section{Enabling hazard risk governance}

In light of the ways in which workshop participants were able to negotiate and situate climate change and local flood risk, the final element of the workshop discussions considered how flooding could be managed differently in the future and what role a place-based community-led approach could have in this process. Discussion of local flood management was initially framed in the workshops within the context of a reliance on the state to act, as the following extract of DA's frustration with a drainage issue exemplifies:

"The other biggest problem I notice is the humungous number of organisations involved ... it took me as a councillor there...nearly a year to get the Highways to speak to the landowner. I gave them the name, serial number, address, every detail - 'Please, just get a slipway, so at the lowest point it can just drain off into the river.' It's those bureaucratic issues to be honest.... which prevent people on the ground facilitating" (DA).

Yet despite this initially sceptical perspective, there was a growing sense that it would be possible for the group to begin to fill the space between state and individual and to carve out an agenda that was positive and pro-active. As the following quotation from $\mathrm{BH}$ notes, there was a focus on what collaborative learning could bring and a sense that the process and content of the experiences of the group could be shared more widely:

"There are things about what I do with my neighbours..."I think it was one of the pennies that dropped for me, it's about this "franchise model", if you like, around thinking, "Why Crediton? 
Crediton's nothing unusual. Most towns have undramatic, but annoying, flood-risk problems. Well, guess what? So does everybody else.' So, if there's something we can learn from this, maybe it's the sort of learning that we can apply elsewhere" (BH).

The sense that the group could act as a catalyst for local and regional collaboration was progressively framed positively in relation to agencies that might at the start have been regarded as holding the only viable knowledge in the field, and the only power. Yet there became a drive to develop knowledge networks and shared learning:

"We're saying to the Environment Agency, 'And, by the way, guys, look at what we're doing down here but, by crikey, there's some stuff you can be doing as well'. If there are folks around who've got stuff to bring to the table about local response, or to ask questions about it, let's all come together and share ideas.' So, yeah, I think with anything like this, it is always an issue about networking. How can we share this? Where do we take this?" (BH).

The avenue that the group took to develop their ideas was to explore how their work could become part of a wider network of community resilience. Through initial suggestions and then a series of informal meetings, community exhibitions and a visual presence in the local public library, the group has now become part of the local Transition group, Sustainable Crediton:

"This just strikes me as such an obvious crossover to Sustainable Crediton, and maybe that would be a useful forum to take this on as this group waves a fond farewell, as it were" (BH).

In practice, this means that the group now acts as a local knowledge creator and adviser in the field of flooding, providing feedback and insights via Sustainable Crediton when planning applications are received. However, perhaps the most notable output of the group was its 2016 report (Figure 3), in which the group articulated to those in and around the town the work they had been undertaking and the conclusions they had reached. A key extract is provided in Box 1 and demonstrates the space which the group created as one that simultaneously seeks to explore ways of generating community capacity to deal with flooding, whilst also integrating itself into existing planning and lobbying networks. In this way, the group has begun to create a space for enabling resilience that is both challenging existing authorities and encouraging a 'more than individual' view of resilience.

\section{Discussion}

We have argued throughout this paper that the out turn of both individually-focused paternalistic policies (Jones et al., 2013) and a focus on hierarchical forms of knowledge construction (Lane et al., 2011) has resulted in a bi-polar scaling of flooding knowledge and governance. On the one hand, the nation state has presented a hard, engineered view of flooding, in which defences will provide safety 
from the rising waters (HM Government, 2008). On the other, prescriptions of personal preparedness are rolled out (Environment Agency, 2016). We argue that both of these (paternalistic) scales of knowledge acquisition and governance are dis-empowering and dysfunctional because they rely on expert-derived knowledges and they reduce rather than promote resilience in a changing climate. In contrast, we argue that community-centred social learning can provide a vital tool for collective learning and participation as an alternative to up-scaled and often remote debates about environmental controversies, through exploring an apparently global concern (climate change) within a specific hazard and geographical setting. We refer to this process as one of enablement; that is, a process which places emphasis on community-scaled initiatives that are both pedagogically valuable and realise the potential of place-based approaches to managing environmental risk. Through using social learning as a methodology (Pahl-Wostl, 2006) our research demonstrates that publics recognise the complex, varied and contingent nature of knowledge about the environment and the challenges surrounding evidence, responsibility and action. We argue that social learning methods can be used as a device to co-develop knowledge and practical action that is both more consensual and empowering. In making this argument, we seek to make three contributions to the literature on the role of expertise (Owens, 2015) and changing citizen-state relationships (Clarke et al., 2007), exploring climate knowledges and the potential for enabling the co-managing environmental hazards.

First, the evidence presented in this paper suggests that traditional relationships between citizens and the state can, in specific settings, become dysfunctional when it comes to tackling environmental hazards. At one level, a discourse of protection and hard resilience promotes the national and local state as the provider of strong and paternalistic protection from the rising waters (HM Government, 2016), as evidenced in our research by the ascription of responsibility to the county highways department. At another level, state-led paternalism is manifested through prescriptive forms of personal resilience measures (Environment Agency, 2016), as highlighted by the ways in which participants in our research talked of personal readiness, wellington boots and 'lifting plugs'. This second approach draws heavily on the rationalistic approach to individual behaviour change (Slovic, 2000; 2010) and the reliance of the UK state on psychological framings of behaviour to manage change (Shove, 2010; Whitehead et al., 2011). But neither of these approaches is enabling, because they dis-empower both communities and individuals to become epistemically empowered to understand and diagnose flooding problems in their own setting. Our workshop sessions demonstrated the narratives of deferring to expert knowledges and the local state, whilst also pushing down responsibility to individual householders. We initially saw no space emerging for a communitybased, locally-inspired approach to hazard governance, but instead a negative often frustrated group of publics, for example as DA noted when the group began its work:: 
"So, but I will stand by what I said - the world is changing, people used to take responsibility for their land. They don't any more. Probably because they don't get a CAP subsidy to do so, like they used to in the old days. So if they're not going to get paid, they just don't do it. The other biggest problem I notice is the humungous number of organisations involved in this thing - the County Council, the District Council, this, that and the other. It's an absolute nightmare. It's an absolute nightmare. So that's the context".

Second, we argue that this position is becoming increasingly untenable and is being challenged, both within the social sciences and also in popular media discourses, as evidenced by narratives on anthropogenic climate change that directly challenge the broad scientific consensus on the impact of carbon emissions (Barr, 2017). Indeed, recent flood events in the UK have highlighted the challenge publics are making to experts about the models they develop and the policies that unfold as a result (BBC, 2014). This has led to questions, in the popular media, about the veracity of scientific knowledge, the politicisation of science and the role of expert-led decision making (Daily Mail, 2017). In particular, there has been a focus on challenging scientific orthodoxies and the policy decisions that emerge from the use of such evidence such that binaries are frequently created in terms of evidence, responsibility and action (BBC, 2014). Yet these are highly conflictual and oppositional discourses; they encourage dis-connected forms of debate amongst publics in a highly charged and negative environment. The evidence provided in this paper suggests that the publics we engaged with appreciated both the complexity of local hazards and the different popular narratives around climate change. However, the focus on a specific hazard and the desire to enact something positive in a local context meant that the final agreed output of the group was able to acknowledge the debate around climate change, whilst also recognising that the threats from flooding were likely to increase. This leads to a different kind of conclusion from that often reached in scientific papers on climate change communication (e.g. Wong-Parodi and Strauss, 2014): that didactic communication of science is often ineffective and that what matters is not an individualistic and absolutist approach to the acceptance of climate science, but rather a collective negotiated acknowledgement of change in the natural environment. We argue here that even though not everyone in our workshops accepted wholesale the science behind climate change, they were nonetheless empowered to think about environmental change and its impact on their community. As such, we ought to be less concerned with the process of mass conversion, but with how communities deal with the changes they understand and want to act on.

Third, we argue that there are major opportunities presented by the potential of such enabling groups to begin the process of re-configuring local governance for environmental hazards and also addressing the wider implications of climate change in such settings. The evidence provided in this 
paper demonstrates the ways in which new forms of community governance can emerge through a knowledge brokering process, that utilise both existing networks and also focus on building community capacity for specific risks (Pahl-Wostll, 2006). Critically, the space occupied by such groups is what we refer to as 'empowered resilience', in which ownership and responsibility is grounded in the local context. Unlike the restrictions of state-led paternalism, this form of local resilience may hold the potential for both challenging the assumptions regarding the causes and impact of environmental hazards, whilst also framing action around collective responsibility, be that through better planning, road maintenance, preparedness and recovery.

Nonetheless, some formidable barriers are evident here. We found in our data that the embeddedness of state paternalism can be profound and deep (for example, DA's comment that: "I hate to say, Highways, I think, are the biggest culprit here"). Our evidence demonstrates the ways in which participants initially held prescribed views on the role of the local and national state and the individualistic nature of preparedness and response. Indeed, there was a sense that any actions to work locally and collaboratively could be negated by lack of co-operation from state actors. Yet we did find that, for various reasons, local state actors were highly encouraging of a localised approach. Moreover, we found that not prescribing, leading, trying to manipulate or manage discussions led to innovative forms of empowered resilience that were the result of creativity rather than theoretical insight.

\section{Conclusion}

The boundaries between discourses on environmental hazards and climate change are becoming progressively blurred. This presents opportunities to explore the issue of climate change through the lens of frequently experienced events like flooding or storm surges. In both cases, national and local states have generally pursued an approach to governing that has both expertised and individualised. Yet this approach is neither functional nor empowering because it simultaneously dis-engages people from the knowledge construction process and also dis-empowers publics from decision making and their attempts to cope, collectively, with hazards. What we end up with is two narratives of disconnection: one that responsibilises through the state and the other through the individual. In arguing for a re-scaling of environmental governance, we call on social scientists to not only realise the opportunities of working at the scale 'in between' these two extremes, but also to craft a research agenda on how the knowledge that is created in such spaces can be mobilised and used to effectively manage hazards through what we term geographies of enablement. This requires challenging the current logics of citizen engagement, which are largely framed around the state as an encourager of directed action, to view the space between the state and individual citizen as one of enablement. Such 
enablement forms in places where the opportunity to challenge existing orthodoxies about environmental hazards management are discussed and creative and practical approaches can emerge. Moreover, such places of enablement are those in which the 'stickiness' of climate change can be outworked with reference to local knowledges and pressing concerns that have meaning.

We do acknowledge that such a shift in governance is challenging and may create tensions between the imperatives of locally-scaled decision making and the interests of neighbouring communities. Indeed, whilst there is evidence for affirming the way that publics participate in the process of knowledge co-production, the translation of such knowledge into sustainable and effective co-management is much more challenging and where further research is required. This does perhaps have much to do with the ways in which individualisation has defined a highly limited understanding of what can be achieved collectively. It also has something to do with a concern that community management of risks could also be regarded as a wholesale devolving of responsibility from the state. Finally, in making the case for such enablement, we as researchers need to deal with fundamental questions of how social scientists practice engaged research and what can realistically emerge. Our reflections on the process of co-producing flood knowledges and negotiating climate change knowledges is that legitimacy is largely something that develops through negotiated and incremental collective confidence-building and an alignment to existing structures of governance. Yet it is also something that can be deeply affirming and opens-up new possibilities for change and resilience building. As such, we ought to be asking how social scientists can promote ways of knowing and coping that promote greater resilience and understanding of issues like climate change. 


\section{References}

Akerlof, K., Rowan, K. E., Fitzgerald, D., \& Cedeno, A. Y. (2012). Communication of climate projections in US media amid politicization of model science. Nature Climate Change, 2(9), 648-654.

Barr, S. (2003). Strategies for sustainability: citizens and responsible environmental behaviour. Area, 35(3), 227240.

Barr, S. (2011). Climate forums: virtual discourses on climate change and the sustainable lifestyle. Area, 43(1), $14-22$.

Barr, S. (2014). Practicing the cultural green economy: where now for environmental social science?. Geografiska Annaler: Series B, Human Geography, 96(3), 231-243.

Barr, S. (2017). Knowledge, Expertise and Engagement. Environmental Values, 26(2), 125-130.

BBC (2014) Somerset floods crisis: How the story unfolded. Online: http://www.bbc.co.uk/news/uk-englandsomerset-26157538. Accessed $28^{\text {th }}$ June 2017.

Becu, N., Amalric, M., Anselme, B., Beck, E. \& Bertin, X.,= =.= (2016). Participatory simulation of coastal flooding: building social learning on prevention measures with decision-makers. Published in the Proceedings of the International Congress on Environmental Modelling and Software, Toulouse, July 2016. Online: https://scholarsarchive.byu.edu/iemssconference/2016/Stream-D/73/. Accessed $18^{\text {th }}$ November 2017.

Behavioural Insights Team (2016) Behavioural Insights Team's Update Report 2015-16 (Behavioural Insights Team, London).

Berkes, F. (2009). Evolution of co-management: role of knowledge generation, bridging organizations and social learning. Journal of environmental management, 90(5), 1692-1702.

Berkes, F., \& Ross, H. (2013). Community resilience: toward an integrated approach. Society \& Natural Resources, 26(1), 5-20.

Blake, J. (1999). Overcoming the 'value-action gap' in environmental policy: Tensions between national policy and local experience. Local environment, 4(3), 257-278.

Blewitt, J. (2006). The ecology of learning: sustainability, lifelong learning and everyday life. Earthscan.

Centre for Ecology and Hydrology (2016) The winter floods of 2015/2016 in the UK - a review (Centre for Ecology and Hydrology, Wallingford).

Brown, K. (2016) Resilience, Development and Global Change (Routledge, Abingdon).

Callon, M. (1999). The role of lay people in the production and dissemination of scientific knowledge. Science, Technology and Society, 4(1), 81-94.

Carnegie Trust (2011) Exploring Community Resilience. Available at: https://www.carnegieuktrust.org.uk/carnegieuktrust/wpcontent/uploads/sites/64/2016/02/pub1455011679.pdf . Accessed $7^{\text {th }}$ December 2017.

Carvalho, A., \& Burgess, J. (2005). Cultural circuits of climate change in UK broadsheet newspapers, 1985-2003. Risk analysis, 25(6), 1457-1469.

Chilvers, J., \& Kearnes, M. (Eds.). (2015). Remaking participation: Science, environment and emergent publics. Routledge. 
Chilvers, J., \& Longhurst, N. (2016). Participation in transition (s): Reconceiving public engagements in energy transitions as co-produced, emergent and diverse. Journal of Environmental Policy \& Planning, 18(5), 585-607.

Clarke, J., Newman, J., Smith, N., Vidler, E., \& Westmarland, L. (2007). Creating citizen-consumers: Changing publics and changing public services. Pine Forge Press.

Cope, M. \& Kurtz, A. (2016) Organising, coding and analysing qualitative data. In N. Clifford, M. Cope, T. W. Gillespie \& S. French (Ed.) Key Methods in Geography (Sage, London), 647-664. Third edition.

Corner, A., Whitmarsh, L., \& Xenias, D. (2012). Uncertainty, scepticism and attitudes towards climate change: biased assimilation and attitude polarisation. Climatic change, 114(3-4), 463-478.

Daily Mail (2017) Exposed: How world leaders were duped into investing billions over manipulated global warming

data.

Online: $\quad$ http://www.dailymail.co.uk/sciencetech/article-4192182/World-leaders-duped-manipulated-globalwarming-data.html. Accessed $5^{\text {th }}$ July 2017

Demeritt, D. (2001a). The construction of global warming and the politics of science. Annals of the association of American geographers, 91(2), 307-337.

Demeritt, D. (2001b). Science and the understanding of science: A reply to Schneider. Annals of the Association of American Geographers, 91(2), 345-348.

Department for the environment, Food and Rural Affairs (2005) Securing the Future: delivering UK sustainable development strategy (The Stationary Office, London).

Environment Agency (2017) Floods Destroy: be prepared. Online: https://floodsdestroy.campaign.gov.uk/. Accessed $28^{\text {th }}$ June 2017.

French, J., \& Blair-Stevens, C. (2009). Key concepts and principles of social marketing. In Social marketing and public health: theory and practice (pp. 28-43). Oxford University Press, Oxford.

Funtowicz, S. O., \& Ravetz, J. R. (1993). Science for the post-normal age. Futures, 25(7), 739-755.Gauchat, G. (2012). Politicization of science in the public sphere: A study of public trust in the United States, 1974 to 2010. American sociological review, 77(2), 167-187.

Funtowicz, S. O., \& Ravetz, J. R. (1993). Post-normal science: environmental policy under conditions of complexity. Article posted on nusap.net. Online: http://www. nusap.net/sections. php?op=viewarticle\&artid=13. Accessed $24^{\text {th }}$ June 2018.

Giddens, A. (1991). Modernity and self-identity: Self and society in the late modern age. Stanford university press. Griffin, R. J., Dunwoody, S., \& Neuwirth, K. (1999). Proposed model of the relationship of risk information seeking and processing to the development of preventive behaviors. Environmental research, 80(2), S230-S245.

HM Government (2008) The Pitt Review: Learning the Lessons from the 2007 Floods (The Stationary Office, London).

HM Government (2016) National Flood Resilience Review (The Stationary Office, London).

Hopkins, R. (2008). The transition handbook. From oil dependency to local resilience (Green Books, Totnes). House of Lords (2011) Behaviour Change. Report by the Science and Technology Committee of the House of Lords (The Stationary Office, London). 
Hulme, M. (2009). Why we disagree about climate change: Understanding controversy, inaction and opportunity. Cambridge University Press.

Intergovernmental Panel on Climate Change (IPCC) (2015) Climate Change 2014: synthesis report (IPCC, Geneva). Jessop, B. (2002). Liberalism, neoliberalism, and urban governance: A state-theoretical perspective. Antipode, $34(3), 452-472$.

Jones, R., Pykett, J., \& Whitehead, M. (2011a). Governing temptation: Changing behaviour in an age of libertarian paternalism. Progress in human geography, 35(4), 483-501.

Jones, R., Pykett, J., \& Whitehead, M. (2011b). The geographies of soft paternalism in the UK: the rise of the avuncular state and changing behaviour after neoliberalism. Geography Compass, 5(1), 50-62.

Jones, R., Pykett, J., \& Whitehead, M. (2013). Changing behaviours: on the rise of the psychological state. Edward Elgar Publishing.

Kellens, W., Zaalberg, R., Neutens, T., Vanneuville, W., \& De Maeyer, P. (2011). An analysis of the public perception of flood risk on the Belgian coast. Risk Analysis, 31(7), 1055-1068.

Kellens, W., Zaalberg, R., \& De Maeyer, P. (2012). The Informed Society: An Analysis of the Public's InformationSeeking Behavior Regarding Coastal Flood Risks. Risk analysis, 32(8), 1369-1381.

Keogh, D. U., Apan, A., Mushtaq, S., King, D., \& Thomas, M. (2011). Resilience, vulnerability and adaptive capacity of an inland rural town prone to flooding: a climate change adaptation case study of

Charleville, Queensland, Australia. Natural Hazards, 59(2), 699-723.

Kievik, M., \& Gutteling, J. M. (2011). Yes, we can: motivate Dutch citizens to engage in self-protective behavior with regard to flood risks. Natural hazards, 59(3), 1475.

Kollmuss, A., \& Agyeman, J. (2002). Mind the gap: why do people act environmentally and what are the barriers to pro-environmental behavior?. Environmental education research, 8(3), 239-260.

Lane, S. N., Odoni, N., Landström, C., Whatmore, S. J., Ward, N., \& Bradley, S. (2011). Doing flood risk science differently: an experiment in radical scientific method. Transactions of the Institute of British Geographers, 36(1), 15-36.

Lanfranchi, V., Wrigley, S. N., Ireson, N., Wehn, U., \& Ciravegna, F. (2014, May). Citizens' observatories for situation awareness in flooding. In ISCRAM.

Leiserowitz, A. (2006). Climate change risk perception and policy preferences: The role of affect, imagery, and values. Climatic change, 77(1), 45-72.

Lieske, D. J., Wade, T., \& Roness, L. A. (2014). Climate change awareness and strategies for communicating the risk of coastal flooding: a Canadian Maritime case example. Estuarine, Coastal and Shelf Science, 140, 83-94.

Lupton, D. (2013) Risk (Routledge, Abingdon).

Maibach, E., Leiserowitz, A., Cobb, S., Shank, M., Cobb, K. M., \& Gulledge, J. (2012). The legacy of climategate: undermining or revitalizing climate science and policy?. Wiley Interdisciplinary Reviews: Climate Change, 3(3), 289-295

Mann, C. and Toles, T. (2016) The Madhouse Effect: How Climate Change Denial Is Threatening Our Planet, Destroying Our Politics, and Driving Us Crazy (Columbia University Press, New York). 
McEwen, L., Krause, F., Hansen, J. G., \& Jones, O. (2012, July). Flood histories, flood memories and informal flood knowledge in the development of community resilience to future flood risk. In BHS Eleventh National Symposium, Hydrology for a changing world, Dundee (pp. 9-11).

Miceli, R., Sotgiu, I., \& Settanni, M. (2008). Disaster preparedness and perception of flood risk: A study in an alpine valley in Italy. Journal of environmental psychology, 28(2), 164-173.

Mooney, C. (2008) The Republican War on Science (Basic Books, New York).

Moser, S. C. (2010). Communicating climate change: history, challenges, process and future directions. Wiley Interdisciplinary Reviews: Climate Change, 1(1), 31-53.

Nerlich, B., Koteyko, N., \& Brown, B. (2010). Theory and language of climate change communication. Wiley Interdisciplinary Reviews: Climate Change, 1(1), 97-110.Owens, S. (2000). 'Engaging the public': information and deliberation in environmental policy. Environment and planning A, 32(7), 1141-1148.

Oppenheimer, M. 2005. Defining dangerous anthropogenic interference: the role of science, the limits of science. Risk Analysis, 25, 1399-1407.

Owens, S. (2015). Knowledge, Policy, and Expertise: The UK Royal Commission on Environmental Pollution 19702011. OUP Oxford.

Pahl-Wostl, C. (2006). The importance of social learning in restoring the multifunctionality of rivers and floodplains. Ecology and society, 11(1).Rose, N., \& Miller, P. (1992). Political power beyond the state: Problematics of government. British journal of sociology, 61, 173-205.

Ross, H., \& Carter, R. W. (2011). Natural disasters and community resilience. Natursl Hazards, 18, 1-5.

Shove, E. (2010). Beyond the ABC: climate change policy and theories of social change. Environment and planning A, 42(6), 1273-1285.

Shove, E. (2011). On the difference between chalk and cheese-a response to Whitmarsh et al's comments on "Beyond the ABC: climate change policy and theories of social change". Environment and Planning A, 43(2), 262264.

Shuckburgh, E., Robison, R., \& Pidgeon, N. (2012). Climate science, the public and the news media. Summary findings of a survey and focus groups conducted in the UK in March 2011.

Slovic, P. (2000) The Perception of Risk (Earthscan, London).

Slovic, P. (2010) The Feeling of Risk: new perspectives on risk perception (Earthscan, London).

Smith, A., Porter, J. J., \& Upham, P. (2017). "We cannot let this happen again": reversing UK flood policy in response to the Somerset Levels floods, 2014. Journal of Environmental Planning and Management, 60(2), 351369.

Stott, P. A., Christidis, N., Otto, F. E., Sun, Y., Vanderlinden, J. P., van Oldenborgh, G. J., ... \& Zwiers, F. W. (2016). Attribution of extreme weather and climate-related events. Wiley Interdisciplinary Reviews: Climate Change, 7(1), 23-41.

Strauss, A. L. (1987) Qualitative analysis for social scientists. Cambridge University Press, Cambridge.

Thaler, R. H., \& Sunstein, C. R. (1975). Nudge: Improving Decisions About Health, Wealth, and Happiness (Yale University Press, New Haven, Conn.). 
Wachinger, G., Renn, O., Begg, C., \& Kuhlicke, C. (2013). The risk perception paradox-implications for governance and communication of natural hazards. Risk analysis, 33(6), 1049-1065.

Whitehead, M., Jones, R., \& Pykett, J. (2011). Governing irrationality, or a more than rational government? Reflections on the rescientisation of decision making in British public policy. Environment and Planning A, 43(12), 2819-2837.

Whitmarsh, L. (2009). Behavioural responses to climate change: Asymmetry of intentions and impacts. Journal of environmental psychology, 29(1), 13-23.

Wong-Parodi, G., \& Strauss, B. H. (2014). Team science for science communication. Proceedings of the National Academy of Sciences, 111(Supplement 4), 13658-13663.

Wynne, B. (1992) Risk and Social Learning: reificiation to engagement. In In S. Krimsky \& D. Golding (eds.), Social Theories of Risk. Praeger. pp. 275-297. 


\section{Box 1: Crediton Flood Resilience Group summary of findings and actions}

The following provides a summary of the key findings from the group's research so far, which will form the basis of working with Sustainable Crediton to take the work forward:

* Crediton's recent and historic record of flooding is not dramatic or unusual - but in common with many communities, it has had a number of small-scale problems over the years. This means that the findings from this project could be of value to many communities experiencing similar issues;

* Crediton's local incidents are sometimes associated with river flooding, but more commonly from intense rainfall causing high levels of water to run-off farmland and streets to cause flash floods;

* There is widespread agreement that farming practices, highway / storm drain maintenance, riparian maintenance of waterways and new development in the built environment all play a major part in the number and severity of flooding incidents;

* We acknowledge the body of evidence on climate change and how this might affect the intensity and frequency of severe weather in the future. We conclude that it would be wise to plan for the possibility of increasing problems associated with severe weather;

* We recognise that for the foreseeable future, public sector spending will continue to be restricted. As a result, local communities might need to become more proactive and self-reliant in managing these issues;

* At a local level, our priority must be to identify what we might do to lessen the number of future events and to lessen their impact. This might be rephrased as:

- How to reduce or stop flooding from happening;

- How to respond to specific incidents (crisis management);

- How to follow through in the aftermath of specific incidents;

- How to reduce vulnerability from possible events

The Crediton Flood Resilience Group is working to transform these findings into ways that can help make Crediton and its people more resilient to future flooding, especially in the light of evidence that suggest rainfall events may become more frequent and intense in future.

This is being done in these ways:

- By working with Crediton Town Council as they develop their emergency plan for Crediton, ensuring that flooding is fully integrated into this new plan and by providing a basis for helping the community to consider long-term resilience to flooding, both before and after a flood emergency;

- $\quad$ By engaging with and having a partnership approach to working with local agencies. Devon Country Council, the Devon and Somerset Fire and Rescue Authority and the Environment Agency have all been involved with this project and the work of the group and respect and will work with its findings;

- The group has become an affiliate of Sustainable Crediton. By becoming part of a major community group in the area, this will help the flood resilience group to ensure that people in Crediton are involved in understanding, preparing for and reacting to flooding in the future;

- The University of Exeter and the Crediton Flood Resilience Group is working with organisations at the regional level in the South West to promote the research undertaken in Crediton and to learn from the experiences of others about how to promote flood resilience. 
Figure 1: Public exhibition poster exploring historic flood events in Crediton (to 1925) (Source: Credition Flood Resilience Group)

Figure 2: Public exhibition poster exploring historic flood events in Crediton (from 1925) (Source: Credition Flood Resilience Group)

Figure 3: The front page of the 2016 Crediton Flood Resilience Group Report (Source: Credition Flood Resilience Group) 